\section{New therapeutic applications of ozenoxacin in superficial skin infections}

\author{
Gema García Ron, María Villa Arranz \\ 'La Rivota' Healthcare Center, \\ Alcorcón, Madrid, Spain
}

\begin{abstract}
In recent years, the incidence of community-acquired methicillin-resistant $S$. aureus skin infections (CA-MARSA) has increased in pediatric population without associated risk factors. Ozenoxacin $10 \mathrm{mg} / \mathrm{g}$ is a topical quinolone that has shown high activity on strains of $S$. aureus, $S$. pyogenes and other Gram-positive bacteria sensitive and resistant to methicillin, other quinolones, mupirocin and fusidic acid. Ozenoxacin $10 \mathrm{mg} / \mathrm{g}$ cream was applied twice a day for 5 days in pediatric patients with superficial skin infections other than non-bullous impetigo where oral antibiotics were not needed. Therapeutic success was achieved in $93.7 \%$ of the patients after 5 days of treatment, with a $98.2 \%$ decrease in the mean SIRS scale of symptoms. No adverse reaction was reported during treatment. Given the achieved effectiveness, safety, and adherence of the treatment, we believe that pediatricians should consider this topical antibiotic for the treatment of other superficial skin infections, without limiting its use to non-bullous impetigo.
\end{abstract}

\section{Introduction}

The skin is the main structural barrier of the body and any process that alters it can favor the development of an infection. ${ }^{1}$ The skin has a resident or saprophytic microbiota composed of bacteria that support well the acidic and dry environment of the epidermis. When this microbiota is altered, it favors the development of transient microbiota that can trigger infections. ${ }^{1}$ The microorganisms that are most frequently implicated in skin infections are $S$. aureus and $S$. pyogenes (Supplementary Table S1) and it is towards them that empirical antibiotic therapy should be directed. ${ }^{2}$

Skin infections are a frequent reason for consultation in pediatric dermatology, having a wide spectrum of severity. ${ }^{1,3}$ Topical treatment of superficial skin infections is usually enough to treat them, unless there are risk factors in the host, the infections are severe, extensive, or have complications. ${ }^{1}$ In recent years, an increase in the incidence of skin infections caused by communityacquired methicillin-resistant $S$. aureus (CA-MRSA) has been described worldwide, especially in the pediatric population without associated risk factors. ${ }^{3}$ This incidence is especially high in the United States, while in Spain and other countries in Europe it appears to be lower. ${ }^{4}$

Classically, for less extensive superficial skin infections, topical antibiotics such as fusidic acid $2 \%$, mupirocin $2 \%$ or retapamulin 1\% (Supplementary Table S2) have been used, as recommended by clinical practice guidelines. ${ }^{1,5,6}$

In 2018, ozenoxacin $10 \mathrm{mg} / \mathrm{g}$ was marketed in Spain. It is a non-fluoridated quinolone for topical use indicated, according to the product information sheet, for the treatment of non-bullous impetigo (the most common skin infection in pediatric patients) in patients older than 6 months. ${ }^{7}$ Ozenoxacin has a bactericidal mechanism of action due to simultaneous inhibition of the enzymes topoisomerase IV and DNA gyrase, necessary for bacterial replication, by which it produces fast bacterial death. ${ }^{7}$

In vitro microbiological studies have shown that it has a high activity at very low concentrations on $S$. pyogenes and on strains of both, susceptible and methicillin-, fusidic acid or mupirocin resistant strains of S. aureus, causal agents of most uncomplicated superficial infections of the skin. ${ }^{8,9}$ Various studies have shown that ozenoxacin has a very low capacity to generate resistances in vitro, which is attributed to its dual target of action and its rapid bactericidal effect at low concentrations. ${ }^{10,11}$ This powerful bactericidal activity has been evidenced clinically. Of 206 patients with impetigo treated with ozenoxacin in a randomized study, $88.8 \%$ had clinical cure or improvement after 5 days of treatment and the microbiological evaluation showed that after 2 days of treatment, bacterial eradication was of $87,2 \%$ reaching a $92 \%$ after 5 days of treatment. ${ }^{12}$

Ozenoxacin has a good safety and tolerability profile and is not systemically absorbed. As, unlike fluorquinolones, ozenoxacin is not fluorinated, it has not shown chondrotoxicity, phototoxicity, or the induction of contact dermatitis throughout its clinical development.?

Given that most superficial skin infections share the same types of pathogenic microorganisms, ${ }^{2}$ it was decided to empirically determine the usefulness of ozenoxacin $10 \mathrm{mg} / \mathrm{g}$ cream in superficial skin infections other than non-bullous impetigo.

[Dermatology Reports 2022; 14:9289]
Correspondence: Gema García Ron, Healthcare center La Rivota, Calle las Palmeras, 5, 28922 Alcorcón, Madrid, Spain. E-mail: gemagarciaron@hotmail.com

Key words: Ozenoxacin; Skin infection; Antibiotics; Quinolone, S. aureus.

Acknowledgements: The authors would thank José Francisco Albaladejo and Anna Molinet Mateo for the support in the submission of this article.

Contributions: The authors contributed equally.

Conflict of interest: The authors declare no potential conflict of interest.

Funding: None.

Consent statement: Informed consent was obtained from all patients to publish their personal data and images.

Please cite this article as: Garcia Ron G, Villa Arranz M. New therapeutic applications of ozenoxacin in superficial skin infections. Dermatol Rep 2022;14:9289.

Received for publication: 15 June 2021. Accepted for publication: 7 July 2021.

This work is licensed under a Creative Commons Attribution-NonCommercial 4.0 International License (CC BY-NC 4.0).

(C) Copyright: the Author(s), 2021

Licensee PAGEPress, Italy

Dermatology Reports 2022; 14:9289

doi:10.4081/dr.2021.9289

Publisher's note: All claims expressed in this article are solely those of the authors and do not necessarily represent those of their affiliated organizations, or those of the publisher, the editors and the reviewers. Any product that may be evaluated in this article or claim that

\section{Case Reports}

This prospective observational pilot study was conducted from December 2019 to December 2020 in the pediatric service of Centro la Rivota, Alcorcón, Madrid, Spain.

During the time period in which the study was carried out, a total of 16 patients were recruited, 12 males and 4 females. Thirteen of the patients (10 male and 3 female) had local infections of the nail skin fold (paronychias, whitlows) (range 3-14 years). Two patients (both males) had folliculitis (range 4-6 years) and one patient (female) aged 12 years presented with an ear lobe infection secondary to an infection 
of an orifice due to a piercing (Supplementary Table S3).

Pediatric patients between 6 months and 14 years who had superficial skin infections other than non-bullous impetigo in which oral antibiotics, due to severity or extension of the lesions were not needed, were considered for this study. Patients with a history of hypersensitivity to ozenoxacin and patients with impetiginized skin lesions were excluded. At the baseline visit, all the patients and their parents were informed about the procedure to be carried out and the informed consent was signed, which was reflected in their clinical history. All patients continued treatment with 2 daily applications of ozenoxacin $10 \mathrm{mg} / \mathrm{g}$ for 5 days, with a final visit after the end of therapy. The presence of exudate pus, crusts, erythema/inflammation, tissue warmth, pruritus and pain were clinically assessed using the Skin Infection Rating Scale (SIRS) of signs and symptoms grading them from 0-3 (0 absent, 1 minimum, 2 moderate, 3 severe). ${ }^{13}$

The clinical response was based on the clinical assessment by the investigator at the follow-up visit following a predefined scale with the following categories: 1 : Clinical success, 2: Clinical improvement, 3: No change, 4: therapeutic failure, and 5: indeterminate. Clinical success was considered the total absence of the lesion or improvement based on the SIRS scale so that the score was 0 (absent) for exudate/pus, crusts, itching and pain and no more than 1 (minimum) for erythema/inflammation. and that no additional antimicrobial therapy was required.

A picture of the lesion was taken at baseline and another at the end of therapy. No samples were taken for microbiological determination. As this is a first proof of concept study, no sample size was calculated, and no statistical analysis was previewed beside descriptive statistics of the variables.

After the topical administration of ozenoxacin $10 \mathrm{mg} / \mathrm{g}$ every $12 \mathrm{~h}$ for 5 days, $93.7 \%$ of the patients achieved clinical success. The mean global score of the SIRS scale decreased 6.4 points $(92.8 \%)$ from the baseline visit to the end of therapy (Figure 1). It was only necessary to associate amoxicillin-clavulanate in one of the cases of paronychia due to lack of complete resolution of the lesion. In another 2 cases of paronychia, a minimal degree of erythema persisted after 5 days of treatment but did not require additional medication. In the cases of folliculitis, the clinical success was $100 \%$, as in the case of the patient with ear lobe infection. In Figures $2 \mathrm{~A}$ and $3 \mathrm{~A}$ two cases of paronychia at baseline can be seen, showing the evolution after 5 days twice a
Lesion evolution

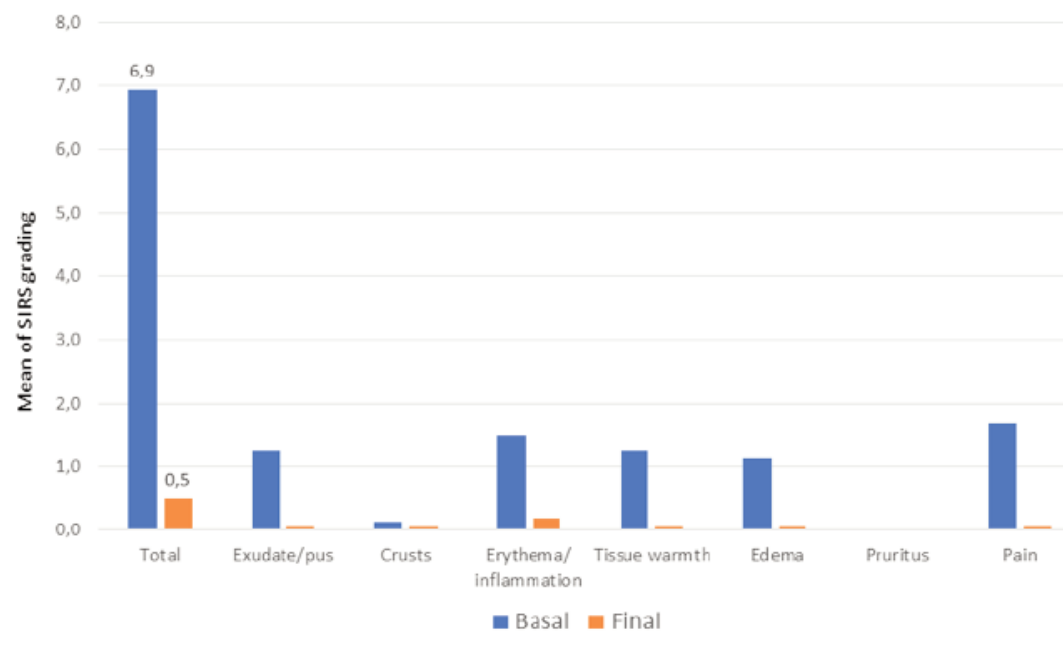

Figure 1. Mean score of SIRS before and after 5 days b.i.d treatment with ozenoxacin $10 \mathrm{mg} / \mathrm{g}$ cream. Symptoms were graded from 0-3 (0 absent, 1 minimum, 2 moderate, 3 severe).

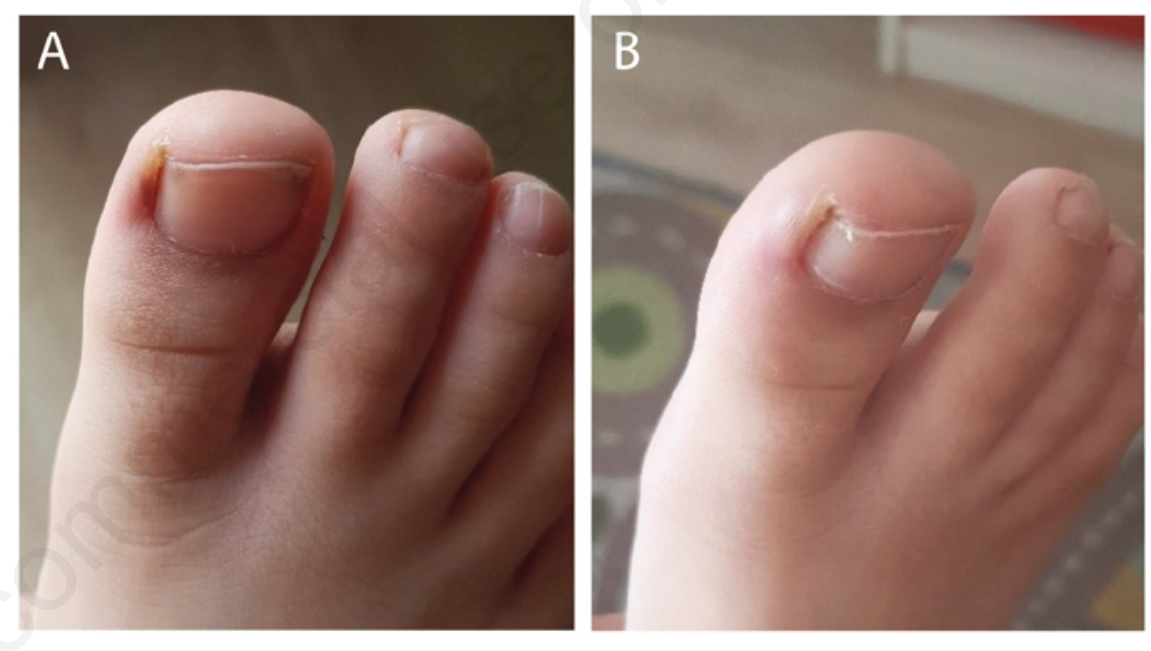

Figure 2. Paronychia at baseline (2A) and after 5 days twice a day therapy (2B) with ozenoxacin $10 \mathrm{mg} / \mathrm{g}$.
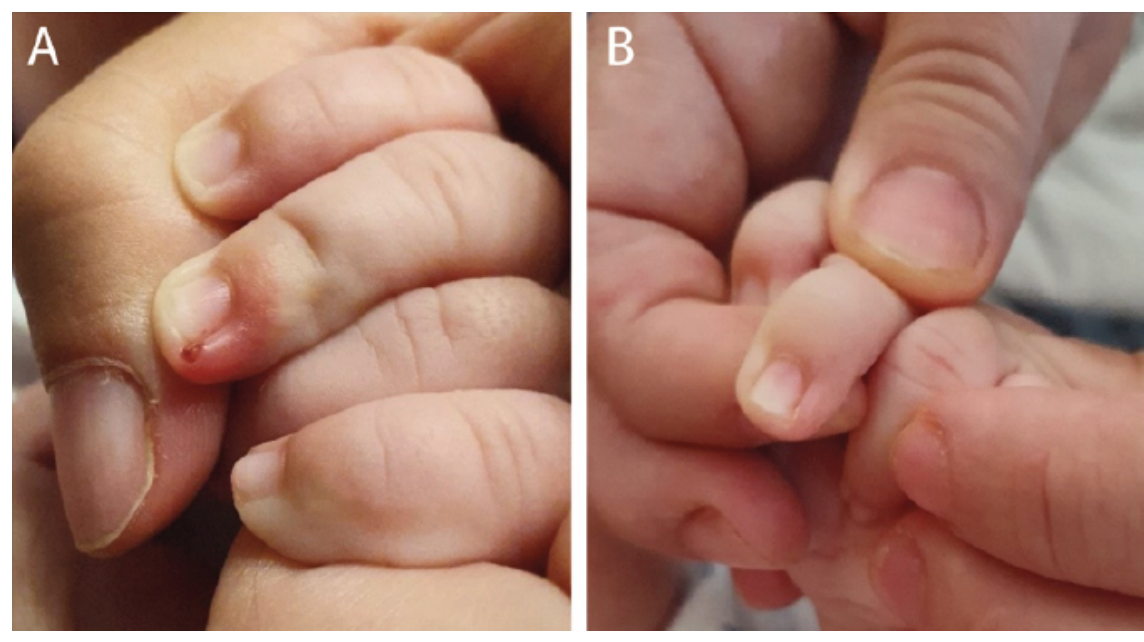

Figure 3. Paronychia at baseline (3A) and after 5 days twice a day therapy (3B) with ozenoxacin $10 \mathrm{mg} / \mathrm{g}$. 
day treatment with ozenoxacin $10 \mathrm{mg} / \mathrm{g}$ cream (Figures 2 and 3). Additional pictures from the initial lesions and follow up of the evolution in this study can be found in the Appendix.

In all cases, the tolerability of the drug was very good, with no signs of local irritation or any other local or systemic alterations.

\section{Discussion and conclusions}

For many years, only fusidic acid, first marketed in the 1960 s and mupirocin, first marketed in 1987 in the USA and in 1991 in the EU, were available as topical antibiotics for superficial skin infections. Retapamulin was marketed in 2007 but for commercial reasons it was withdrawn from the market in 2019 in EU. Both mupirocin and fusidic acid are indicated in all types of superficial skin infections, primary infections as impetigo or folliculitis, as well as secondary treatment of impetiginization of eczematous lesions or secondary infection of wounds and lacerations. ${ }^{14,15}$

The excessive use or misuse of these topical antibiotics have led to an increase in resistances to mupirocin and fusidic acid, which varies significantly depending on the geographic location and local data. Since in this type of pathologies the treatment is usually empirical, it is difficult to find data in the literature that reflect the real state of the resistance rate to these topical antibiotics. In the United States, a study in pediatric patients with superficial skin and soft tissue infections (SSTIs) has shown resistance to mupirocin in up to $31 \%$ of the included patients. ${ }^{16}$ New Zealand a significant increase in out-of-hospital use of fusidic acid between 1993 and 2012 was reported. In parallel, the prevalence of fusidic acid resistance to $S$. aureus increased from $17 \%$ in 1999 to $29 \%$ in 2013 . The restriction of the free dispensation of mupirocin in that country in the 2000 was followed by a decrease in resistance to mupirocin from $28 \%$ to $11 \%$ in 2011.4

In Spain there are practically no available data on resistance to fusidic acid or mupirocin in outpatients, although recent data in children under 14 years of age which were nasal carriers showed a $2.2 \%$ of resistance to fusidic acid in $S$. aureus and $5.6 \%$ in MRSA16 and a 7\% resistance to mupirocin in $\mathrm{S}$. aureus and a $4 \%$ in MRSA. ${ }^{17}$

The development of ozenoxacin followed the requirements for the development of new antibiotics for skin infections published in the FDA 2010 Guidance for
Industry. ${ }^{18}$ In this guidance, only impetigo is considered as a primary infection with enough entity to demonstrate the efficacy and safety of topical antibiotic treatment. For this reason, only patients with impetigo were included in the clinical trials during ozenoxacin clinical development.

There are no previous studies showing the efficacy of ozenoxacin in the treatment of other superficial skin infections other than impetigo, but the data of our study show that our results are in line with those obtained with mupirocin or fusic acid. Thus, in a comparative study between mupirocin and fusidic acid that included patients with primary and secondary skin lesions (including impetigo) with a treatment schedule of 3 times a day for 7 days application, the patients treated with mupirocin achieved clinical cure or improvement in $97 \%$ of cases and fusidic acid in 93\%. ${ }^{19}$ Additionally, in another comparative study between mupirocin and fusidic acid, the subgroup of patients who presented superficial skin infections other than impetigo achieved clinical cure or improvement after 6-8 days of treatment 3 times a day in $82 \%$ of the patients treated with mupirocin and in $98 \%$ of those treated with fusidic acid. ${ }^{20}$

Even though ozenoxacin $10 \mathrm{mg} / \mathrm{g}$ is indicated only for the topical treatment of non-bullous impetigo in the product information sheet, in view of the results obtained in our study, we believe that its use in other superficial skin infections different from impetigo could be beneficial.

We believe that the success of the treatment relies in its bactericidal activity and in the convenience of the therapeutic schedule of one application every 12 hours for 5 days, as this fact avoids the loss of dose as a consequence of school hours, improving the compliance of the therapy.

It is true that the sample size is not very high and there are also no studies in the literature with which to compare our results, or that compare the efficacy of ozenoxacin $10 \mathrm{mg} / \mathrm{g}$ in other superficial skin lesions compared to the rest of the existing topical antibiotics. To our knowledge, this is the first study conducted with ozenoxacin $10 \mathrm{mg} / \mathrm{g}$ beyond non-bullous impetigo.

However, given the obtained effectiveness data, the safety of the treatment, since no adverse reaction was reported, and the ease of compliance with the treatment, we consider that pediatricians should take this topical antibiotic into account for the treatment of other superficial skin infections caused by susceptible microorganisms and do not restrict its use only to non-bullous impetigo.

\section{References}

1. Cobo Vázquez E, Saavedra Lozano J. Infecciones de la piel y partes blandas (I): impétigo, celulitis, absceso (v.3/2019). Guía_ABE. Infecciones en Pediatría. Guía rápida para la selección del tratamiento antimicrobiano empírico. http://www.guia-abe.es. Updated April 7, 2019. Accessed February 23, 2021

2. Larru B, Gerber JS. Cutaneous bacterial infections caused by Staphylococcus aureus and Streptococcus pyogenes in infants and children. Pediatr Clin North Am 2014;61:457-78.

3. Conejo-Fernández AJ, MartínezChamorro MJ, Couceiro JA, et al. Documento de consenso SEIP-AEPAPSEPEAP sobre la etiología, el diagnóstico y el tratamiento de las infecciones cutáneas bacterianas de manejo. Ann Pediatr 2016;84:121.

4. Williamson DA, Monecke S, Heffernan $\mathrm{H}$, et al. High usage of topical fusidic acid and rapid clonal expansion of fusidic acid-resistant Staphylococcus aureus: a cautionary tale. Clin Infect Dis 2014;59:1451-4.

5. Stevens DL, Bisno AL, Chambers HF, et al. Infectious Diseases Society of America. Practice guidelines for the diagnosis and management of skin and soft tissue infections: 2014 update by the Infectious Diseases Society of America. Clin Infect Dis 2014;59:e1052.

6. Fortuny C, Corretger JM, Noguera A, et al. Guía de terapéutica antimicrobiana en pediatría. 3rd ed. Madrid, Spain: Ed. Escofet-Zamora; 2019.

7. Ozanex (ozenoxacino) 10mg/g crema. Ferrer. Available from: https://cima. aemps.es/cima/dochtml/ft/82357/FT_8 2357.html Published 2018. Accessed February 7, 2021

8. Canton R, Morrissey I, Vila J, et al. Comparative in vitro antibacterial activity of ozenoxacin against Gram-positive clinical isolates. Future Microbiol 2018;13:3-19

9. Morrissey I, Cantón R, Vila J, et al. Microbiological profile of ozenoxacin. Future Microbiol 2019;14:773-87.

10. López Y, Tato M, Espinal P, et al. In vitro selection of mutants resistant to ozenoxacin compared with levofloxacin and ciprofloxacin in Gram-positive cocci. J Antimicrob Chemother 2015;70:57-61.

11. López Y, Tato M, Gargallo-Viola D, et al. Mutant prevention concentration of ozenoxacin for quinolone-susceptible 
or -resistant Staphylococcus aureus and Staphylococcus epidermidis. PLoS One 2019; 14:e0223326.

12. Rosen T, Albareda N, Rosenberg N, et al. Efficacy and safety of ozenoxacin cream for treatment of adult and pediatric patients with impetigo: a randomized clinical trial. JAMA Dermatol 2018;154:806-13.

13. Bohaty BR, Choi S, Cai C, Hebert AA. Clinical and bacteriological efficacy of twice daily topical retapamulin ointment $1 \%$ in the management of impetigo and other uncomplicated superficial skin infections. Int J Womens Dermatol 2015;1:13-20.

14. Bactroban (mupirocina) $20 \mathrm{mg} / \mathrm{g}$ pomada. Stiefel Farma S.A. https://cima.aemps.es/cima/dochtml/ft/ 58868/FT 58868.html Published 2008. Accessed March 3, 2021.
15. Fucidine (Ácido Fusídico) 20mg/g crema. Leo Pharma. https://cima.aemps.es/cima/dochtml/ft/ 82357/FT_82357.html Published 2010. Accessed March 3, 2021.

16. Antonov NK, Garzon MC, Morel KD, et al. High prevalence of mupirocin resistance in Staphylococcus aureus isolates from a pediatric population. Antimicrob Agents Chemother 2015;59:3350-6.

17. del Rosal T, Méndez-Echevarría A, García-Vera C, et al. Staphylococcus aureus nasal colonization in Spanish children. The COSACO Nationwide Surveillance Study. Infect Drug Resist 2020;13:464351.

18. Guidance for Industry. Acute bacterial skin and skin structure infections: developing drugs for treatment. draft guidance. U.S. Department of Health and Human Services Food and Drug Administration Center for Drug Evaluation and Research (CDER) August 2010 Clinical/Antimicrobial Revision https://www.fda. gov/files/ drugs/published/Acute-Bacterial-Skinand-Skin-Structure-Infections-Developing-Drugs-for-Treatment.pdf

19. White DG, Collins PO, Rowsell RB. Topical antibiotics in the treatment of superficial skin infections in general practice - a comparison of mupirocin with sodium fusidate. J Infect 1989;18: 221-9.

20. Morley PA, Munot LD. A comparison of sodium fusidate ointment and mupirocin ointment in superficial skin sepsis. Curr Med Res Opin 1988;11: 142-8. 